\title{
Evaluation of epidermal growth factor receptor serum levels and their association with clinicopathological characteristics in patients with colorectal cancer
}

\author{
MEHMET KARABULUT ${ }^{1}$, CIGDEM USUL AFSAR $^{2}$, HALIL ALIS $^{1}$, \\ EBRU ORAN ${ }^{1}$, SENEM KARABULUT $^{3}$, CEVHER AKARSU $^{1}$, NURI ALPER SAHBAZ ${ }^{1}$, \\ ALPEN YAHYA GÜMÜSOGLU $^{1}$, ELIF BILGIN ${ }^{4}$ and NURI FARUK AYKAN ${ }^{5}$
}

\author{
${ }^{1}$ Clinic of General Surgery, Istanbul Bakırkoy Dr Sadi Konuk Education and Research Hospital, 34147 Istanbul; \\ ${ }^{2}$ Clinic of Medical Oncology, Bakirkoy Acibadem Hospital, 34140 Istanbul; ${ }^{3}$ Clinic of Medical Oncology, Istanbul Bakirkoy \\ Dr Sadi Konuk Education and Research Hospital, 34147 Istanbul; Departments of ${ }^{4}$ Basic Oncology \\ and ${ }^{5}$ Medical Oncology, Institute of Oncology, Istanbul University, 34093 Istanbul, Turkey
}

Received June 16, 2016; Accepted March 9, 2017

DOI: $10.3892 / \mathrm{mco} .2017 .1405$

\begin{abstract}
Colorectal cancer (CRC) is a major public health concern and one of the leading causes of cancer-related mortality worldwide. The aim of the present study was to determine the serum epidermal growth factor receptor (sEGFR) levels in healthy volunteers and patients with $\mathrm{CRC}$, to determine the association between tumor marker levels and clinicopathological findings, and investigate its prognostic value. A total of 140 patients with CRC were enrolled in the present study. Pre-treatment sEGFR levels were determined using ELISA. A total of 40 age- and sex-matched healthy controls were included in the analysis. The median age of patients was 60 years (range, 24-84 years); the majority of the tumor localization was to the colon $(n=81,58 \%)$. The median follow-up time was 14 months, while $43(31 \%)$ patients experienced disease progression and $31(22 \%)$ succumbed to the disease. A total of 81 patients $(58 \%)$ were in the early stages of disease (stage II and III), and $42 \%$ of the patients had stage IV disease. The estimated 2-year overall and 1-year progression-free survival rates for the whole patient group were $70 \%$ [95\% confidence interval (CI): 58.8-81.2] and 26.2\% (95\% CI: 12.9-39.5), respectively. The number of patients who received neoadjuvant treatment was 37 . Of the patients who were administered palliative treatment, 24 received oxaliplatin, whereas 22 received irinotecan and 9 received fluorouracil/capecitabine. A total of 36 and 15 of the patients who received targeted therapy were administered bevacizumab and cetuximab, respectively. Of
\end{abstract}

Correspondence to: Dr Cigdem Usul Afsar, Clinic of Medical Oncology, Bakırkoy Acıbadem Hospital, 1 Halit Ziya Usaklıgil Cd., Zeytinlik Mahallesi, 34140 Istanbul, Turkey

E-mail: cigdemusul@yahoo.com

Key words: epidermal growth factor receptor, serum, diagnostic, clinicopathological characteristics, colorectal cancer the 55 patients with metastatic disease who received palliative chemotherapy (CTx), 31\% were CTx-responsive. The baseline median sEGFR levels were significantly higher in patients with CRC compared with the healthy control group $(\mathrm{P}=0.002)$. In addition, established clinical variables, including no surgical resection, metastatic stage, higher pathological tumor stage, poorer regression score (3-4) and higher lactate dehydrogenase levels, were found to be associated with higher sEGFR levels $(\mathrm{P}=0.03, \mathrm{P}=0.009, \mathrm{P}=0.05, \mathrm{P}=0.05$ and $\mathrm{P}=0.05$, respectively). The results of the present study did not reveal statistically significant associations between sEGFR concentrations and overall and progression-free survival rates. In conclusion, sEGFR concentrations may be diagnostic markers in patients with CRC; however, their predictive and prognostic values were not determined.

\section{Introduction}

Colorectal cancer (CRC) is a common and lethal disease. CRC incidence and mortality rates vary markedly worldwide. Globally, CRC is the third most commonly diagnosed cancer in men and the second in women, with an estimated $>1.2$ million new cases and 608,700 CRC-related deaths in 2008 (1). Specific genetic changes are considered to drive the transformation from normal colonic epithelium to invasive cancer, and these genetic mutations may be inherited or acquired (2). CRC represents an ideal model for the study of the molecular pathogenesis of cancer, due to the accessibility of tissue for biopsy and the clear progression from normal colonic epithelium to invasive cancer via an intermediate precursor, the adenomatous polyp (2).

Several blood biomarkers have been investigated in CRC, including circulating microRNA, endothelial cell specific molecule-1, neutrophil/lymphocyte ratio, platelet/lymphocyte ratio, $\alpha-2$ macroglobulin, KRAS and epidermal growth factor receptor (EGFR) (3-9).

EGFR is a $170-\mathrm{kDa}$ glycoprotein that belongs to the transmembrane tyrosine kinase receptor family, and has 
been detected in a wide variety of cancer types (10). The activation of EGFR has multiple consequences, such as cell growth, differentiation and proliferation; it also promotes malignant transformation, angiogenesis and metastatic dissemination (10). EGFR has been reported to be overexpressed in the majority $(50-80 \%)$ of colorectal tumors, and its expression has been demonstrated to be associated with poor outcome in patients with stage IV disease (11-14).

Mourtzikou et al (15) identified that serum (s)EGFR levels were significantly lower in the patient group when compared with those in healthy control individuals. In this previous study, there was no significant association between tumor-node-metastasis (TNM) stage, histological grade, performance status and EGFR expression (15). Few studies have reported an association between histological grade and EGFR overexpression $(16,17)$, whereas a number of investigators consider the clinicopathological characteristics of colon carcinoma not to be affected by EGFR expression $(18,19)$. However, in certain studies, a higher sEGFR level at baseline was associated with the best objective response and may be considered a significant predictor of outcome in patients with advanced CRC (9).

The present study aimed to determine the sEGFR levels in healthy volunteers and patients with $\mathrm{CRC}$, to determine the association between the levels of this tumor marker and clinicopathological findings, and to investigate its prognostic value.

\section{Patients and methods}

Study design and eligibility criteria. The serum samples of 140 consecutive patients with CRC who were referred to Istanbul University Institute of Oncology and Bakirkoy Dr. Sadi Konuk Training and Research Hospital (Istanbul, Turkey) between May 2011 and August 2014 were obtained. The median age of the patients was 60 years (range, 24-84 years). All the patients were staged using the seventh edition of the American Joint Committee on Cancer TNM system (20) on a radiological and pathological basis.

All the patients were treated with a multidisciplinary approach. Patients with colon cancer who had undergone surgery including segmental colon resection were treated with adjuvant chemotherapy (CTx) according to their stage. Patients with rectal cancer, who received neoadjuvant radiochemotherapy (RCTx) or radiotherapy (RT), had undergone low anterior resection or abdominoperineal resection. Certain patients underwent palliative surgery and stage IV patients received palliative CTx, with or without targeted therapy (bevacizumab or cetuximab). The pretreatment evaluation included detailed clinical history and physical examination, with a series of biochemistry tests and complete blood cell count. Selection for treatment required an Eastern Cooperative Oncology Group (ECOG) performance status score of 0-2 (21), and appropriate bone marrow (hemoglobin $>9 \mathrm{~g} / \mathrm{dl}$, absolute neutrophil count $>1,500 / \mu 1$ and platelet count $>100,000 / \mu 1$ ), cardiac, renal and hepatic function.

Patients were treated with various CTx regimens, including single-agent or combination therapy. Regimens of single or combination CTx were selected according to the performance status of the patients and extension of disease. Patients received one of the following treatment regimens: Simplified
LV5FU2 (leucovorin $400 \mathrm{mg} / \mathrm{m}^{2}$, followed by 5-fluorouracil as a $400 \mathrm{mg} / \mathrm{m}^{2}$ bolus and a 2,400 $\mathrm{mg} / \mathrm{m}^{2}$ infusion over $46 \mathrm{~h}$ every 2 weeks), capecitabine $\left(1,000 \mathrm{mg} / \mathrm{m}^{2}\right.$, twice daily, oral administration, for 14 days of each 21-day cycle), modified FOLFOX regimen (simplified LV5FU2 regimen plus oxaliplatin $85 \mathrm{mg} / \mathrm{m}^{2}$ every 2 weeks), FOLFIRI (simplified LV5FU2 regimen plus irinotecan $180 \mathrm{mg} / \mathrm{m}^{2}$ every 2 weeks), XELOX (capecitabine $1,000 \mathrm{mg} / \mathrm{m}^{2}$, twice daily, oral administration, for 14 days plus oxaliplatin $130 \mathrm{mg} / \mathrm{m}^{2}$ every 3 weeks), or XELIRI (capecitabine $1,000 \mathrm{mg} / \mathrm{m}^{2}$, twice daily, oral administration, for 14 days plus irinotecan $240 \mathrm{mg} \mathrm{m}^{2}$ every 3 weeks). Bevacizumab was given at a dose schedule of either $5 \mathrm{mg} / \mathrm{kg}$ every 2 weeks or $7.5 \mathrm{mg} / \mathrm{kg}$ every 3 weeks. Cetuximab $500 \mathrm{mg} / \mathrm{m}^{2}$ was administered intravenously every 2 weeks.

All the patients underwent pretreatment imaging of primary tumors using magnetic resonance imaging (MRI) or computed tomography (CT) scan. For patients with evaluable imaging studies prior to and following treatment, the radiological response was evaluated according to the Response Evaluation Criteria in Solid Tumors (version 1.1) (22) and classified as follows: Complete response (CR), partial response (PR), stable disease (SD) or progressive disease (PD). The tumor response after 2 months of CTx was used for statistical analysis. Follow-up programs for metastatic disease consisted of clinical and laboratory programs and CT scan or MRI, depending on which imaging methods were used at baseline, and performed at 8-week intervals during CTx or every 12 weeks for patients receiving no anticancer treatment. Patients with either a CR or PR were classified as responders, and patients with an SD or PD were considered non-responders.

The present study was approved by the Institutional Review Board (IRB) of Istanbul University, Institute of Oncology (Istanbul, Turkey). Baseline demographic, clinical and laboratory data, including age, sex, performance status, tumor marker levels, KRAS mutation status and treatment details, were obtained retrospectively for all patients using uniform database templates to ensure consistent data collection. The patient comorbidities included cardiac and metabolic diseases.

The control group consisted of 40 age- and sex-matched healthy females with no previous history of malignancy or autoimmune disorders. Blood samples were obtained from patients with CRC at first admission, prior to the administration of any therapy. Blood samples of healthy controls were collected in dry tubes and the sera separated from cellular elements by centrifugation (at 1,431 x g for $10 \mathrm{~min}$ ) within $30 \mathrm{~min}$ following collection. Blood samples were stored at $-80^{\circ} \mathrm{C}$ prior to analysis. All the samples were collected under the approval of the IRB and all the patients provided written informed consent.

Measurement of sEGFR levels. An EGFR ELISA kit (Shanghai Yehua Biological Technology Co.Ltd, Shanghai, China), which uses a double-antibody sandwich ELISA to determine the level of human EGFR in samples, was used according to the manufacturer's protocol. Serum samples and standards were added to the wells, which were pre-coated with human EGFR monoclonal antibody. Streptavidin-horseradish peroxidase was added to form immune complexes and allowed to incubate at $37^{\circ} \mathrm{C}$ for $1 \mathrm{~h}$. Unbound material was washed away, and chro- 
Table I. Patient clinicopathological characteristics.

\begin{tabular}{|c|c|}
\hline Characteristics & No. of patients \\
\hline Total & 140 \\
\hline Age, years, median (range) & $60(24-84)$ \\
\hline Sex, male/female & $96 / 44$ \\
\hline Performance status ${ }^{\mathrm{a}}, 0 / 1 / 2 / 3$ & $68 / 61 / 7 / 1$ \\
\hline Smoking $^{\text {a }}$, yes/no & $61 / 66$ \\
\hline Alcohol intake ${ }^{a}$, yes/no & $26 / 99$ \\
\hline Comorbidities $^{\text {a }}$ yes/no & $56 / 79$ \\
\hline Obstruction, yes/no & $17 / 123$ \\
\hline \multicolumn{2}{|l|}{ Surgery type } \\
\hline Colectomy & 56 \\
\hline Low anterior resection & 36 \\
\hline Abdominoperineal resection & 13 \\
\hline Palliative surgery & 11 \\
\hline pT stage ${ }^{\mathrm{b}}, 0 / 1 / 2 / 3 / 4$ & $9 / 2 / 12 / 45 / 10$ \\
\hline pN stage ${ }^{\mathrm{b}}, 0 / 1 / 2$ & $42 / 18 / 14$ \\
\hline Stage of disease, $2 / 3 / 4$ & $17 / 64 / 59$ \\
\hline Site of lesion, colon/rectum & $81 / 59$ \\
\hline Response to $\mathrm{CTx}^{\mathrm{c}}, \mathrm{CR} / \mathrm{PR} / \mathrm{SD} / \mathrm{PD} / \mathrm{unknown}$ & $2 / 15 / 10 / 24 / 4$ \\
\hline Targeted therapy, bevacizumab/cetuximab & $36 / 15$ \\
\hline Metastasis, yes/no ${ }^{\mathrm{d}}$ & $59 / 81$ \\
\hline
\end{tabular}

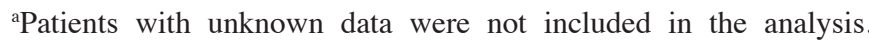
b81 non-metastatic disease patients with unknown data were not included in the analysis. ${ }^{\text {In }} 59$ patients with metastatic CRC. ${ }^{\mathrm{d}}$ Stage II and III. CR, complete response; PR, partial response; SD, stable disease; PD, progressive disease; CTx, adjuvant chemotherapy.

mogen solution was added and incubated at $37^{\circ} \mathrm{C}$ for $10 \mathrm{~min}$ in the dark for the conversion of the colorless solution to a blue solution, the intensity of which is proportional to the amount of EGFR in the sample. Upon the addition of the acidic stop solution, the color was converted to yellow. The colored reaction product was measured using an automated ELISA reader (ChroMate $^{\circledR}$ 4300; Awareness Technology, Inc., Palm City, FL, USA) at $450 \mathrm{~nm}$. The results were expressed as $\mathrm{ng} / \mathrm{ml}$.

Statistical analysis. SPSS for Windows version 21.0 (IBM Corp., Armonk, NY, USA) was employed for data analysis. Continuous variables were categorized using median values as cut-off point. The Chi-square test or one-way analysis of variance were used for group comparison of categorical variables, and the Mann-Whitney U test or Kruskall-Wallis test were used for comparison of continuous variables. The Spearman's rank order correlation was used for correlation analysis. Progression-free survival (PFS) was calculated from the date of admission to the date of first radiological progression, with or without elevated serum tumor marker. Overall survival (OS) was calculated from the date of first admission to the clinic to disease-associated mortality or date of last contact with the patient or any family member. The Kaplan-Meier method was used for the estimation of survival distribution, and variations in PFS and OS were assessed using the log-rank test. All
Table II. Histopathological characteristics and laboratory parameters.

\begin{tabular}{|c|c|}
\hline Variables & No. of patients \\
\hline Histology, adenocarcinoma/mucinous & $129 / 11$ \\
\hline Grade $^{a}, 1 / 2 / 3$ & $8 / 56 / 6$ \\
\hline Angiolymphatic invasion $^{\mathrm{b}}$, yes/no & $30 / 18$ \\
\hline Vascular invasion $^{\mathrm{b}}$, yes/no & $16 / 30$ \\
\hline Perineural invasion ${ }^{\mathrm{b}}$, yes/no & $18 / 28$ \\
\hline Regression score $^{c}, 1 / 2 / 3 / 4$ & $1 / 12 / 4 / 8$ \\
\hline$K R A S$ mutation status ${ }^{\mathrm{d}}$, mutant/wild-type & $24 / 28$ \\
\hline \multicolumn{2}{|l|}{ Lactate dehydrogenase, $\mathrm{IU} / \mathrm{ml}^{\mathrm{a}}$} \\
\hline Normal $(<450)$ & 97 \\
\hline High $(>450)$ & 16 \\
\hline \multicolumn{2}{|l|}{ Albumin, $\mathrm{g} / \mathrm{dl}^{\mathrm{a}}$} \\
\hline Normal (>4) & 54 \\
\hline Low $(<4)$ & 58 \\
\hline \multicolumn{2}{|l|}{ Carcinoembryonic antigen, $\mathrm{ng} / \mathrm{ml}^{\mathrm{a}}$} \\
\hline Normal $(<5)$ & 78 \\
\hline $\operatorname{High}(>5)$ & 17 \\
\hline \multicolumn{2}{|l|}{ Carbohydrate antigen $19-9, \mathrm{U} / \mathrm{ml}^{\mathrm{a}}$} \\
\hline Normal $(<38)$ & 81 \\
\hline High $(>38)$ & 28 \\
\hline
\end{tabular}

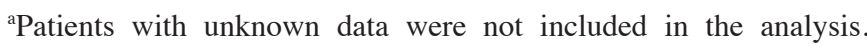
b81 non-metastatic disease patients with unknown data were not included in the analysis. ${ }^{\text {c } 37}$ patients with rectal cancer who received neoadjuvant treatment. ${ }^{\mathrm{d}} 59$ patients with metastatic colorectal cancer.

statistical tests were two-sided and $\mathrm{P} \leq 0.05$ was considered to indicate a statistically significant difference.

\section{Results}

In total, 140 patients who were pathologically diagnosed with CRC between May 2011 and August 2014 were included in the present study. The baseline demographic and histopathological/laboratory characteristics of patients are presented in Tables I and II. The median age of the patients was 60 years (range, 24-84 years). Males constituted the majority of the group $(n=96,69 \%)$. A total of 43 of the patients had a family history of cancer, including 12 with a history of lung cancer and 14 with a history of CRC. The tumor localization was to the rectum in $42 \%(n=59)$ and the colon in $58 \%(n=81)$ of the patients (right colon, $n=17$; hepatic flexure, $n=5$; transverse colon, $\mathrm{n}=5$; descending colon, $\mathrm{n}=13$; splenic flexure, $\mathrm{n}=1$; sigmoid colon, $n=37$; recto-sigmoid junction, $n=6$; and multiple synchronous colon tumors, $\mathrm{n}=3$ ). The most frequent metastatic sites were the liver $(n=40,67.8 \%)$ and the peritoneum $(n=17$, $28.8 \%)$. The rates of synchronous $(n=34)$ and metachronous metastases $(\mathrm{n}=25)$ were 57.6 and $42.4 \%$, respectively.

Of the 37 patients with rectal cancer, 28 received fluoropyrimidine-based RCTx, whereas 9 received short-course RT. A total of 71 patients who had adjuvant CTx received one 
Table III. Serum marker levels in patients with colorectal cancer and healthy controls.

\begin{tabular}{lcccccr}
\hline \multirow{2}{*}{ Marker } & \multicolumn{2}{c}{ Patients $(\mathrm{n}=140)$} & & \multicolumn{2}{c}{ Controls $(\mathrm{n}=40)$} \\
\cline { 2 - 3 } & Median & Range & & Median & Range & P-value \\
\hline sEGFR level $(\mathrm{ng} / \mathrm{ml})$ & 1704.39 & $107.57-75,230.81$ & & 1154.77 & $146.02-2,425.55$ & 0.002 \\
\hline
\end{tabular}

EGFR, serum epidermal growth factor receptor.

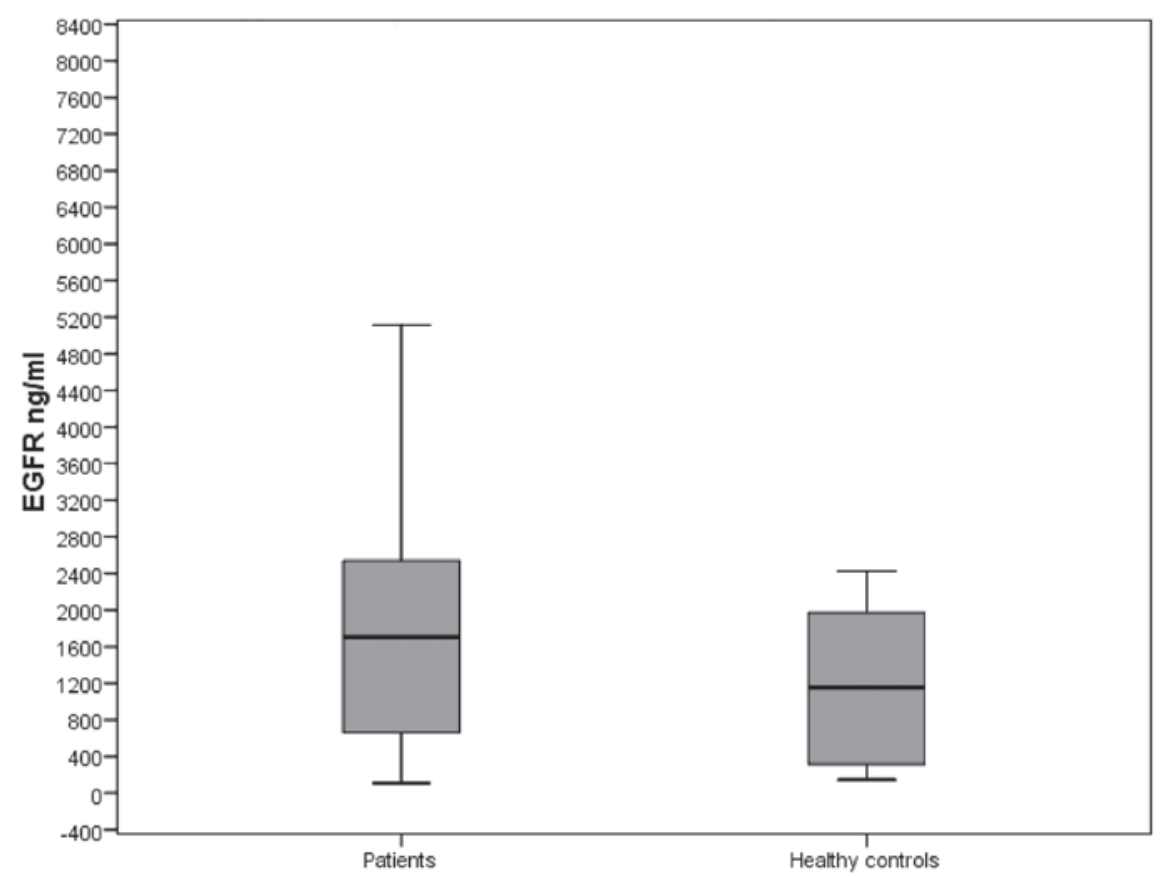

Figure 1. The values of serum EGFR assays in patients with colorectal cancer and controls ( $\mathrm{P}=0.002)$. EGFR, epidermal growth factor receptor.

of the following treatment regimens: Simplified LV5FU2 or capecitabine $(n=14), \operatorname{mFOLFOX}(n=26)$ or XELOX $(n=31)$. Oxaliplatin- and irinotecan-based combination CTx regimens and single-agent fluoropyrimidine were used in 24, 22 and 9 patients, respectively. Bevacizumab was administered to 36 patients, whereas 15 patients received cetuximab as a targeted agent. A response to CTx was observed in $31 \%$ of the 55 metastatic patients who received palliative CTx.

The levels of sEGFR in patients with CRC and healthy controls are presented in Table III. The baseline sEGFR levels were significantly higher compared with the control group (1704.39 vs. 1154.77 ng/ml, respectively; P=0.002; Fig. 1).

The associations between the levels of sEGFR and clinicopathological factors are presented in Tables IV and V. No surgical resection, metastatic status, higher pathological tumor stage, poorer regression score (3-4) and higher lactate dehydrogenase (LDH) levels were significantly associated with higher sEGFR concentrations (all P-values <0.05).

The median follow-up time was 14.0 months (range, 1-34 months), 43 patients (31\%) experienced disease progression, and 31 patients (22\%) succumbed to the disease. The median PFS and OS of the whole group were $7.3 \pm 1.0$ months [95\% confidence interval (CI): 5-9 months] and 26.9 \pm 1.1 months
(95\% CI: 25-29 months), respectively. The 1-year PFS rate was 26.2\% (95\% CI: 12.9-39.5); the 1- and 2-year OS rates were 82.7\% (95\% CI: 76.23-89.17) and 70.0\% (95\% CI: 58.83-81.17), respectively. Univariate analyses were used to evaluate the impact of clinical factors and biomarkers on prognosis. The Kaplan-Meier method and the log-rank test were performed for univariate analysis of PFS and OS. A significant association was observed between other clinicopathological variables, including presence of metastasis $(\mathrm{P} \leq 0.05)$, no surgical resection $(\mathrm{P}=0.01), \mathrm{CTx}$ unresponsiveness $(\mathrm{P}=0.001)$, high serum levels of carcinoembryonic antigen $(\mathrm{CEA})(\mathrm{P}=0.04)$ and carbohydrate antigen (CA) 19-9 $(\mathrm{P}=0.03)$, and poorer PFS (Tables VI and VII). There were significant associations between other clinicopathological variables, including the localization to the rectum $(\mathrm{P}=0.03)$, presence of metastasis $(\mathrm{P}<0.001)$, vascular invasion $(\mathrm{P}=0.02)$, perineural invasion $(\mathrm{P}=0.03)$, poor grade $(\mathrm{P}=0.02)$, low performance status $(\mathrm{P}=0.04)$, no surgical resection $(\mathrm{P}<0.001), \mathrm{CTx}$ unresponsiveness $(\mathrm{P}=0.002)$, high serum levels of LDH $(\mathrm{P}=0.02), \mathrm{CEA}(\mathrm{P}<0.001)$ and CA 19-9 $(\mathrm{P}<0.001)$, low serum levels of albumin $(\mathrm{P}=0.02)$ and poor OS (Tables VIII-X). However, sEGFR levels revealed no significantly adverse association with PFS and OS $(\mathrm{P}=0.12$ and $\mathrm{P}=0.11$, respectively; Tables VII and X; Figs. 2 and 3). 
Table IV. Results of comparisons between the serum assays and various demographic and disease characteristics.

\begin{tabular}{|c|c|c|c|}
\hline Variables & $\mathrm{n}$ & Median EGFR, ng/ml (range) & P-value \\
\hline Age, years & & & 0.33 \\
\hline$<50$ & 22 & $2,024.03(108.99-75,230.81)$ & \\
\hline$\geq 50$ & 118 & $1,438.93(107.57-74,615.28)$ & \\
\hline Sex & & & 0.81 \\
\hline Male & 96 & $1,444.55(107.57-75,230.81)$ & \\
\hline Female & 44 & $1,843.02(108.99-74,615.28)$ & \\
\hline PS & & & 0.11 \\
\hline 0 & 68 & $1,035.47(107.57-50,143.55)$ & \\
\hline $1-3$ & 69 & $1,971.00(108.99-75,230.81)$ & \\
\hline Smoking & & & 0.54 \\
\hline Yes & 61 & $1,397.52(107.57-74,615.28)$ & \\
\hline No & 66 & $1,602.51(108.99-75,230.81)$ & \\
\hline Alcohol intake & & & 0.87 \\
\hline Yes & 26 & $1,147.23(107.57-49,116.45)$ & \\
\hline No & 99 & $1,491.57(108.99-75,230.81)$ & \\
\hline Comorbidity & & & 0.35 \\
\hline Yes & 56 & $1906.43(107.57-75230.81)$ & \\
\hline No & 79 & $1,251.54(316.09-74,615.28)$ & \\
\hline Obstruction & & & 0.38 \\
\hline Yes & 17 & $1,713.44(108.99-75,230.81)$ & \\
\hline No & 123 & $1,491.57(107.57-12,141.99)$ & \\
\hline Surgery & & & $0.03^{\mathrm{b}}$ \\
\hline Yes & 116 & $1,422.22(107.57-75,230.81)$ & \\
\hline No & 24 & $2,379.78(421.16-67,643.89)$ & \\
\hline pT stage & & & $0.05^{\mathrm{b}}$ \\
\hline $0-2$ & 23 & $775.65(316.09-14,169.16)$ & \\
\hline $3-4$ & 55 & $1,695.33(107.57-74,615.28)$ & \\
\hline pN stage & & & 0.42 \\
\hline 0 & 42 & $928.57(107.57-61,069.96)$ & \\
\hline $1-2$ & 32 & $1,444.55(108.99-74,615.28)$ & \\
\hline Metastasis & & & $0.009^{\mathrm{b}}$ \\
\hline Yes & 59 & $2,110.26(146.02-75,230.81)$ & \\
\hline $\mathrm{No}^{\mathrm{a}}$ & 81 & $1,020.79(107.57-74,615.28)$ & \\
\hline Response to CTx & & & 0.76 \\
\hline Yes (CR + PR) & 17 & $1,938.57(261.50-49,116.45)$ & \\
\hline No (SD + PD) & 34 & $2,230.25(146.02-75,230.81)$ & \\
\hline Targeted therapy & & & 0.37 \\
\hline Bevacizumab & 36 & $1,964.50(146.02-49,116.45)$ & \\
\hline Cetuximab & 15 & 2,484.01 (289.30-67,643.89) & \\
\hline Site of lesion & & & 0.56 \\
\hline Colon & 81 & $1,397.52(146.02-61,069.96)$ & \\
\hline Rectum & 59 & $1,938.57(107.57-75,230.81)$ & \\
\hline
\end{tabular}

${ }^{a}$ Stage II and III. ${ }^{b} \mathrm{P} \leq 0.05$. EGFR, epidermal growth factor receptor; CTx, adjuvant chemotherapy; CR, complete response; PR, partial response; $\mathrm{SD}$, stable disease; $\mathrm{PD}$, progressive disease; PS, performance status.

\section{Discussion}

CRC is a major public health concern, with continuously increasing incidence rates (23). In previous years, notable steps forward in the molecular characterization of advanced CRC have been taken. A multiplicity of serum markers have been proposed for early diagnosis of $\mathrm{CRC}$, estimation of the disease extent and monitoring patient treatment $(24,25)$.

EGFR has been detected in a wide variety of cancer types, for some of which its overexpression has been suggested to 
Table V. Results of comparisons between the serum assays and various histopathological features and laboratory parameters.

\begin{tabular}{|c|c|c|c|}
\hline Variables & $\mathrm{n}$ & Median EGFR, ng/ml (range) & P-value \\
\hline Histology & & & 0.39 \\
\hline Adenocarcinoma & 129 & $1,695.33(107.57-74,615.28)$ & \\
\hline Mucinous & 11 & $2,123.79(381.62-75,230.81)$ & \\
\hline Grade & & & 0.51 \\
\hline Good & 8 & $660.74(409.65-8,747.00)$ & \\
\hline Intermediate & 56 & $793.17(316.09-8,450.66)$ & \\
\hline Poor & 6 & $1,365.48(107.57-74,615.28)$ & \\
\hline Angiolymphatic invasion & & & 0.33 \\
\hline Yes & 30 & $1,661.01(107.57-74,615.28)$ & \\
\hline No & 18 & $810.37(313.61-50,143.55)$ & \\
\hline Vascular invasion & & & 0.23 \\
\hline Yes & 30 & $1,661.01(450.65-74,615.28)$ & \\
\hline No & 16 & $887.92(108.99-74,615.28)$ & \\
\hline Perineural invasion & & & 0.19 \\
\hline Yes & 18 & $1,661.01(450.65-74,615.28)$ & \\
\hline No & 28 & $887.92(108.99-50,143.55)$ & \\
\hline Regression score & & & $0.05^{\mathrm{a}}$ \\
\hline $0-2$ & 13 & $771.67(316.09-2,462.00)$ & \\
\hline $3-4$ & 12 & $1,971.00(323.61-61,069.96)$ & \\
\hline$K R A S$ mutation status & & & 0.63 \\
\hline Mutant & 24 & $2,326.84(146.02-67,643.89)$ & \\
\hline Wild-type & 28 & $2,185.89(261.50-74,615.28)$ & \\
\hline LDH & & & $0.05^{\mathrm{a}}$ \\
\hline Normal & 97 & $1,397.52(107.57-75,230.81)$ & \\
\hline High & 16 & $2,495.07(316.09-67,643.89)$ & \\
\hline Albumin & & & 0.83 \\
\hline Normal & 54 & $993.87(261.50-75,230.81)$ & \\
\hline Low & 58 & $2,063.38(107.57-74,615.28)$ & \\
\hline CEA & & & 0.56 \\
\hline Normal & 78 & $1,704.39(107.57-74,615.28)$ & \\
\hline High & 17 & $1,971.00(108.99-26,493.59)$ & \\
\hline CA19-9 & & & 0.45 \\
\hline Normal & 81 & $1,695.33(107.57-75,230.81)$ & \\
\hline High & 28 & $2,030.53(146.02-74,615.28)$ & \\
\hline
\end{tabular}

${ }^{\mathrm{a}} \mathrm{P} \leq 0.05 . \mathrm{LDH}$, lactate dehydrogenase; CEA, carcinoembryonic antigen; CA, carbohydrate antigen.

be a factor associated with poor prognosis and more aggressive clinical progression (10). EGFR expression has been demonstrated to be associated with poor outcome in patients with stage IV CRC (11-14). However, sEGFR levels and their diagnostic, prognostic and predictive roles in CRC have not been investigated in detail.

For non-small-cell lung carcinoma patients, higher sEGFR levels have been found to be significantly associated with a higher OS, and the pre-treatment sEGFR levels constituted an independent prognostic factor (26). For advanced CRC, in the majority of the studies, the clinico- pathological characteristics of colon carcinoma are not affected by EGFR expression $(18,19)$; however, in certain studies, a higher sEGFR level at baseline was associated with the best objective response and may be considered a significant predictor of outcome in patients with advanced CRC (9). In the present study, the baseline sEGFR level was significantly higher compared with the control group (1704.39 vs. $1154.77 \mathrm{ng} \mathrm{ml}$; $=0.002$ ), whereas no surgical resection, metastatic stage, higher pathological tumor stage, poorer regression status (3-4) and higher LDH levels were found to be correlated with higher sEGFR concentrations 
Table VI. Univariate analyses of progression-free survival according to patient and disease characteristics.

\begin{tabular}{|c|c|c|c|c|}
\hline \multirow[b]{2}{*}{ Variables } & \multirow[b]{2}{*}{ Event no./total no. } & \multicolumn{3}{|c|}{ Progression-free survival (months) } \\
\hline & & Median survival $( \pm \mathrm{SE})$ & 1-year survival, \% $( \pm \mathrm{SE})$ & P-value \\
\hline All patients & $43 / 140$ & $7.3(1.0)$ & $26.2(6.8)$ & \\
\hline Age, years & & & & 0.45 \\
\hline$<50$ & $6 / 22$ & $8.3(2.2)$ & Not reached & \\
\hline$\geq 50$ & $37 / 118$ & $7.2(1.1)$ & $25.0(7.2)$ & \\
\hline Sex & & & & 0.46 \\
\hline Male & $29 / 96$ & $7.5(1.1)$ & $28.6(8.5)$ & \\
\hline Female & $14 / 44$ & $7.1(2.1)$ & Not reached & \\
\hline PS & & & & 0.30 \\
\hline 0 & $11 / 68$ & $8.7(2.1)$ & Not reached & \\
\hline $1-3$ & $32 / 69$ & $6.9(1.2)$ & $24.1(7.9)$ & \\
\hline Obstruction & & & & 0.43 \\
\hline Yes & $6 / 17$ & $6.3(1.9)$ & Not reached & \\
\hline No & $33 / 123$ & $7.4(1.1)$ & $24.2(7.5)$ & \\
\hline Surgery & & & & $0.01^{\mathrm{b}}$ \\
\hline Yes & $32 / 116$ & $8.3(1.2)$ & $31.3(8.2)$ & \\
\hline No & $11 / 24$ & $4.2(1.3)$ & Not reached & \\
\hline pT stage & & & & 0.85 \\
\hline $0-2$ & $2 / 23$ & $11.0(3.2)$ & Not reached & \\
\hline $3-4$ & $8 / 55$ & $10.0(6.0)$ & Not reached & \\
\hline pN stage & & & & 0.20 \\
\hline 0 & $4 / 42$ & $6.5(3.2)$ & Not reached & \\
\hline $1-2$ & $6 / 32$ & $13.7(3.7)$ & Not reached & \\
\hline Metastasis & & & & $0.05^{\mathrm{b}}$ \\
\hline Yes & $33 / 59$ & $6.3(0.9)$ & $21.9(7.3)$ & \\
\hline $\mathrm{No}^{\mathrm{a}}$ & $10 / 81$ & NR & Not reached & \\
\hline Response to CTx & & & & $0.001^{\mathrm{b}}$ \\
\hline Yes (CR + PR) & $4 / 17$ & $14.8(2.3)$ & Not reached & \\
\hline No (SD + PD) & $27 / 34$ & $4.1(0.6)$ & Not reached & \\
\hline Targeted therapy & & & & 0.06 \\
\hline Bevacizumab & $21 / 36$ & $7.3(1.2)$ & $28.6(9.9)$ & \\
\hline Cetuximab & $4 / 15$ & $3.5(1.2)$ & Not reached & \\
\hline Site of lesion & & & & 0.18 \\
\hline Colon & $19 / 81$ & $8.3(1.4)$ & $33.3(11.1)$ & \\
\hline Rectum & $24 / 59$ & $6.6(1.3)$ & $20.8(8.3)$ & \\
\hline Histology & & & & 0.79 \\
\hline Adenocarcinoma & $37 / 129$ & $8.2(2.6)$ & $24.3(7.1)$ & \\
\hline Mucinous & $5 / 11$ & $7.2(1.1)$ & Not reached & \\
\hline Grade & & & & 0.79 \\
\hline Good & $1 / 8$ & NR & $9.0(0.0)$ & \\
\hline Intermediate & $13 / 56$ & NR & $7.5(2.2)$ & \\
\hline Poor & $2 / 6$ & NR & $5.5(2.5)$ & \\
\hline Regression score & & & & 0.90 \\
\hline $0-2$ & $2 / 12$ & $9.5(6.5)$ & Not reached & \\
\hline $3-4$ & $0 / 13$ & $4.0(0.0)$ & Not reached & \\
\hline$K R A S$ mutation status & & & & 0.14 \\
\hline Mutant & $14 / 24$ & $4.9(1.2)$ & Not reached & \\
\hline Wild-type & $14 / 28$ & $7.6(1.7)$ & Not reached & \\
\hline
\end{tabular}

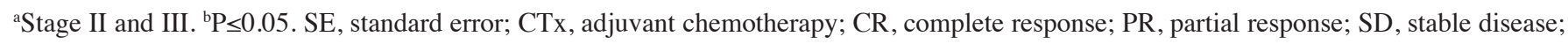
$\mathrm{PD}$, progressive disease. 
Table VII. Univariate analyses of progression-free survival according to laboratory parameters.

Progression-free survival (months)

\begin{tabular}{lccc} 
Variables & Event no./total no. & Median survival $( \pm$ SE $)$ & 1-year survival, $\%( \pm$ SE $)$ \\
\hline LDH & & & $25.9(8.4)$ \\
Normal & $27 / 97$ & $7.1(1.1)$ & NR \\
High & $5 / 16$ & $12.6(5.0)$ & $26.3(10.7)$ \\
Albumin & & & $41.7(14.2)$ \\
Normal & $12 / 54$ & $7.6(1.6)$ & 0.14 \\
Low & $19 / 58$ & $8.9(2.1)$ & $43.8(12.4)$ \\
CEA & & & NR \\
Normal & $16 / 78$ & $8.9(1.5)$ & 0.57 \\
High & $9 / 17$ & $5.2(2.1)$ & $38.9(11.5)$ \\
CA19-9 & & & $21.1(9.4)$ \\
Normal & $18 / 81$ & $9.1(1.3)$ & $0.04^{\mathrm{a}}$ \\
High & $19 / 28$ & $6.5(1.7)$ & $31.3(11.6)$ \\
EGFR & & & $23.1(8.3)$
\end{tabular}

${ }^{a} \mathrm{P} \leq 0.05$. NR, not reached; LDH, lactate dehydrogenase; CEA, carcinoembryonic antigen; CA, carbohydrate antigen; EGFR, epidermal growth factor receptor; SE, standard error.

\section{Survival Functions}



Figure 2. Progression-free survival curves in patients with colorectal cancer according to serum EGFR levels ( $\mathrm{P}=0.12)$. EGFR, epidermal growth factor receptor.

(all P-values <0.05). However, sEGFR levels exhibited no significantly adverse association with PFS and OS $(\mathrm{P}=0.12$ and $\mathrm{P}=0.11$, respectively).

A previous study by Mourtzikou et al (15) revealed that sEGFR levels were significantly lower in the patient group when compared with those in healthy control individuals; however,



Figure 3. Overall survival curves in patients with colorectal cancer according to serum EGFR levels $(\mathrm{P}=0.11)$. EGFR, epidermal growth factor receptor.

these authors collected blood samples from 20 patients with $\mathrm{CRC}$ at a preoperative state and from 30 patients undergoing chemotherapy, which may have affected the study results. In another study performed by Zampino et al (9), the greater the sEGFR level at baseline, the lower the risk of no clinical 
Table VIII. Univariate analyses of overall survival according to patient and disease characteristics.

\begin{tabular}{|c|c|c|c|c|}
\hline \multirow[b]{2}{*}{ Variables } & \multirow[b]{2}{*}{ Event no./total no. } & \multicolumn{3}{|c|}{ Overall survival (months) } \\
\hline & & $\begin{array}{l}\text { Median survival } \\
\text { ( } \pm \text { standard error) }\end{array}$ & $\begin{array}{l}\text { 1-year survival, \% } \\
\text { ( } \pm \text { standard error) }\end{array}$ & P-value \\
\hline All patients & $31 / 140$ & $26.9(1.1)$ & $82.7(3.3)$ & \\
\hline Age, years & & & & 0.30 \\
\hline$<50$ & $4 / 22$ & $22.1(1.4)$ & $90.9(6.1)$ & \\
\hline$\geq 50$ & $27 / 118$ & $26.8(1.2)$ & $81.1(3.8)$ & \\
\hline Sex & & & & 0.76 \\
\hline Male & $20 / 96$ & $26.3(1.3)$ & $83.3(4.0)$ & \\
\hline Female & $11 / 44$ & 26.7 (1.9) & $81.5(5.9)$ & \\
\hline PS & & & & $0.02^{\mathrm{b}}$ \\
\hline 0 & $9 / 68$ & $25.4(1.7)$ & $87.5(4.2)$ & \\
\hline $1-3$ & $22 / 69$ & $23.1(0.9)$ & $77.3(5.2)$ & \\
\hline Obstruction & & & & 0.50 \\
\hline Yes & $5 / 17$ & $20.7(2.0)$ & $81.1(9.9)$ & \\
\hline No & $23 / 123$ & $27.5(1.3)$ & $83.1(3.6)$ & \\
\hline Surgery & & & & $<0.001^{\mathrm{b}}$ \\
\hline Yes & $20 / 116$ & $28.6(1.1)$ & $88.0(3.1)$ & \\
\hline No & $11 / 24$ & $13.3(2.0)$ & $56.9(10.4)$ & \\
\hline pT stage & & & & 0.28 \\
\hline $0-2$ & $0 / 23$ & NR & $100.0(0.0)$ & \\
\hline $3-4$ & $3 / 55$ & NR & $98.2(1.8)$ & \\
\hline $\mathrm{pN}$ stage & & & & 0.43 \\
\hline 0 & $1 / 42$ & $32.3(0.7)$ & $97.6(2.4)$ & \\
\hline $1-2$ & $2 / 32$ & $32.3(1.2)$ & $100.0(0.0)$ & \\
\hline Metastasis & & & & $<0.001^{\mathrm{b}}$ \\
\hline Yes & $27 / 59$ & $15.9(1.4)$ & $61.1(6.8)$ & \\
\hline $\mathrm{No}^{\mathrm{a}}$ & $4 / 81$ & NR & $97.5(1.7)$ & \\
\hline Response to CTx & & & & $0.002^{\mathrm{b}}$ \\
\hline Yes (CR + PR) & $2 / 17$ & $23.6(1.6)$ & $93.3(6.4)$ & \\
\hline No (SD + PD) & $19 / 34$ & $11.9(1.4)$ & $47.6(9.4)$ & \\
\hline Targeted therapy & & & & 0.55 \\
\hline Bevacizumab & $13 / 36$ & $17.8(1.7)$ & $69.9(8.6)$ & \\
\hline Cetuximab & $7 / 15$ & $15.2(2.8)$ & $52.5(13.1)$ & \\
\hline Site of lesion & & & & $0.03^{\mathrm{b}}$ \\
\hline Colon & $8 / 81$ & $29.2(1.2)$ & $91.0(3.8)$ & \\
\hline Rectum & $23 / 59$ & 24.7 (1.6) & $76.6(4.9)$ & \\
\hline
\end{tabular}

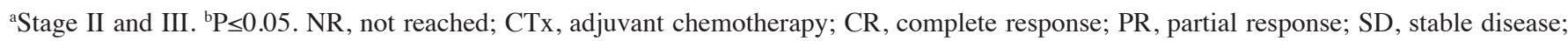
$\mathrm{PD}$, progressive disease.

response; furthermore, a higher sEGFR at baseline was associated with the best objective response to EGFR-targeted therapy and may be considered as a significant predictor of outcome in patients with advanced CRC.

In conclusion, CRC is a major public health concern and its incidence rates continue to increase. Research into the biology of CRC has identified a large number of tumor markers that provide diagnostic, prognostic or predictive information. The present study demonstrated that sEGFR concentrations may be diagnostic markers in patients with CRC. However, their predictive and prognostic values were not determined. 
Table IX. Univariate analyses of overall survival according to histopathological characteristics.

\begin{tabular}{|c|c|c|c|c|}
\hline \multirow[b]{2}{*}{ Variables } & \multirow[b]{2}{*}{ Event no./total no. } & \multicolumn{3}{|c|}{ Overall survival (months) } \\
\hline & & Median survival $( \pm \mathrm{SE})$ & 1-year survival, \% $( \pm \mathrm{SE})$ & P-value \\
\hline Histology & & & & 0.48 \\
\hline Adenocarcinoma & $28 / 129$ & $27.7(1.1)$ & $84.4(3.3)$ & \\
\hline Mucinous & $3 / 11$ & $18.5(2.7)$ & $70.7(14.3)$ & \\
\hline Grade & & & & $0.02^{\mathrm{a}}$ \\
\hline Good & $0 / 8$ & NR & $100.0(0.0)$ & \\
\hline Intermediate & $6 / 56$ & NR & $90.7(4.0)$ & \\
\hline Poor & $3 / 6$ & NR & $66.7(19.2)$ & \\
\hline Angiolymphatic invasion & & & & 0.25 \\
\hline Yes & $3 / 30$ & NR & $96.6(3.4)$ & \\
\hline No & $0 / 18$ & NR & $100.0(0.0)$ & \\
\hline Vascular invasion & & & & $0.02^{\mathrm{a}}$ \\
\hline Yes & $3 / 16$ & NR & $93.3(6.4)$ & \\
\hline No & $0 / 30$ & NR & $100.0(0.0)$ & \\
\hline Perineural invasion & & & & $0.03^{\mathrm{a}}$ \\
\hline Yes & $3 / 18$ & NR & $94.1(5.7)$ & \\
\hline No & $0 / 28$ & NR & $100.0(0.0)$ & \\
\hline Regression score & & & & 0.30 \\
\hline $0-2$ & $1 / 12$ & NR & $91.7(8.0)$ & \\
\hline $3-4$ & $0 / 13$ & NR & $100.0(0.0)$ & \\
\hline$K R A S$ mutation status & & & & 0.25 \\
\hline Mutant & $13 / 24$ & $15.1(2.0)$ & $52.6(10.3)$ & \\
\hline Wild-type & $8 / 28$ & $18.2(2.1)$ & $75.8(9.7)$ & \\
\hline
\end{tabular}

${ }^{\mathrm{a} P} \leq 0.05$. NR, not reached; SE, standard error.

Table X. Univariate analyses of overall survival according to laboratory parameters.

\begin{tabular}{lccc}
\hline & & & Overall survival (months) \\
Variables & Event no./total no. & Median survival $( \pm$ SE) & 1-year survival, $\%( \pm$ SE) \\
\hline LDH & & & $84.6(3.8)$ \\
Normal & $21 / 97$ & $21.5(0.9)$ & $62.5(12.1)$ \\
High & $7 / 16$ & $20.5(3.8)$ & $0.02^{\mathrm{a}}$ \\
Albumin & & & $89.8(4.3)$ \\
Normal & $7 / 54$ & $23.2(1.0)$ & $73.7(5.8)$ \\
Low & $20 / 58$ & $23.4(1.9)$ & $95.7(2.5)$ \\
CEA & & & $68.0(12.2)$ \\
Normal & $7 / 78$ & $24.4(0.6)$ & $0.02^{\mathrm{a}}$ \\
High & $6 / 17$ & $17.9(2.6)$ & $93.4(2.9)$ \\
CA19-9 & & & $61.5(9.7)$ \\
Normal & $10 / 81$ & $23.8(0.7)$ & $80.001^{\mathrm{a}}$ \\
High & $13 / 28$ & $20.0(2.8)$ & $84.7(4.5)$ \\
EGFR & & & $80.6(4.9)$ \\
$<$ Median & $12 / 70$ & $28.8(1.4)$ & $<0.001^{\mathrm{a}}$ \\
$>$ Median & $19 / 70$ & $20.1(1.2)$ & 0.11 \\
\hline
\end{tabular}

${ }^{a} \mathrm{P} \leq 0.05$. SE, standard error; EGFR, epidermal growth factor receptor; CA, carbohydrate antigen; CEA, carcinoembryonic antigen; LDH, lactate dehydrogenase. 


\section{References}

1. Jemal A, Bray F, Center MM, Ferlay J, Ward E and Forman D: Global cancer statistics. CA Cancer J Clin 61: 69, 2011.

2. Ionov Y, Peinado MA, Malkhosyan S, Shibata D and Perucho M: Ubiquitous somatic mutations in simple repeated sequences reveal a new mechanism for colonic carcinogenesis. Nature 363: $558-561,1993$

3. Nonaka R, Miyake Y, Hata T, Kagawa Y, Kato T, Osawa H, Nishimura J, Ikenaga M, Murata K, Uemura M, et al: Circulating miR-103 and miR-720 as novel serum biomarkers for patients with colorectal cancer. Int J Oncol 47: 1097-1102, 2015.

4. Jiang H, Fu XG and Chen YT: Serum level of endothelial cell-specific molecule-1 and prognosis of colorectal cancer. Genet Mol Res 14: 5519-5526, 2015.

5. Jia J, Zheng X, Chen Y, Wang L, Lin L, Ye X, Chen Y, Chen D and Dettke M: Stage-dependent changes of preoperative neutrophil to lymphocyte ratio and platelet to lymphocyte ratio in colorectal cancer. Tumour Biol 36: 9319-9325, 2015.

6. Šunderić M, Šedivá A, Robajac D, Miljuš G, Gemeiner P, Nedić $\mathrm{O}$ and Katrlík J: Lectin-based protein microarray analysis of differences in serum alpha-2-macroglobulin glycosylation between patients with colorectal cancer and persoons without cancer. Biotechnol Appl Biochem 63: 457-464, 2016.

7. Li Y, Fu XH, Yuan JQ, Yang ZY, Mao C, Dong XM, Tang JL and Wang SY: Colorectal cancer: Using blood samples and tumor tissue to detect K-ras mutations. Expert Rev Anticancer Ther 15: 715-725, 2015

8. Takahashi N, Yamada Y, Furuta K, Nagashima K, Kubo A, Sasaki Y, Shoji H, Honma Y, Iwasa S, Okita N, et al: Association between serum ligands and the skin toxicity of anti-epidermal growth factor receptor antibody in metastatic colorectal cancer. Cancer Sci 106: 604-610, 2015.

9. Zampino MG, Magni E, Santoro L, Zorzino L, Dell'Orto P, Sonzogni A, Fazio N, Monfardini L, Chiappa A, Biffi R and de Braud F: Epidermal growth factor receptor serum (sEGFR) level may predict response in patients with EGFR-positive advanced colorectal cancer treated with gefitinib? Cancer Chemother Pharmacol 63: 139-148, 2008.

10. Spano JP, Lagorce C, Atlan D, Milano G, Domont J, Benamouzig R, Attar A, Benichou J, Martin A, Morere JF, et al: Impact of EGFR expression on colorectal cancer patient prognosis and survival. Ann Oncol 16: 102-108, 2005.

11. Cheirsilpa A, Ruangvejvorachai P, Karalak A, Sangprakarn S, Pummai S and Sangrajrang S: Determination of epidermal growth factor receptor (EGFR) in patients with colorectal cancer. Cancer Ther 5: 137-142, 2007.

12. Arteaga CL: The Epidermal Growth Factor Receptor: From Mutant Oncogene in Non-human Cancers to Therapeutic Target in Human Neoplasia. J Clin Oncol 19 (18 Suppl): 32S-40S, 2001

13. Yarden Y: The EGFR family and its ligands in human cancer signalling mechanisms and therapeutic opportunities. Eur J Cancer 37 (Suppl 4): S3-S8, 2001.

14. Goldstein NS and Armin M: Epidermal growth factor receptor immunohistochemical reactivity in patients with American Joint Committee on Cancer Stage IV colon adenocarcinoma: Implications for a standardized scoring system. Cancer 92: $1331-1345,2001$
15. Mourtzikou A, Stamouli M, Kroupis C, Christodoulou S, Skondra M, Kastania A, Pectasides D, Athanasas G and Dimas C: Evaluation of carcinoembryonic antigen (CEA), epidermal growth factor receptor (EGFR), epithelial cell adhesion molecule EpCAM (GA733-2), and carbohydrate antigen 19-9 (CA 19-9) levels in colorectal cancer patients and correlation with clinicopathological characteristics. Clin Lab 58: 441-448, 2012.

16. Guo GF, Cai YC, Zhang B, Xu RH, Qiu HJ, Xia LP, Jiang WQ, $\mathrm{Hu}$ PL, Chen XX, Zhou FF and Wang F: Overexpression of SGLT1 and EGFR in colorectal cancers showing a correlation with the prognosis. Med Oncol 28 (Suppl 1): S197-S203, 2011.

17. McKay JA, Murray LJ, Curran S, Ross VG, Clark C, Murray GI, Cassidy J and McLeod HL: Evaluation of the epidermal growth factor receptor (EGFR) in colorectal tumors and lymph node metastases. Eur J Cancer 38: 2258-2264, 2002.

18. Mohhamadi G, Jamialahmadi K, Lary S and Ghaffarzadegan K: Expression of membranousepidermalgrowthfactorreceptor in colorectal adenocarcinoma and its correlation with clinico pathological features. Pak J Biol Sci 14: 357-362, 2011.

19. Abd El All HS, Mishriky AM and Mohamed FA: Epidermal growth factor receptor in colorectal carcinoma: Correlation with clinico-pathological prognostic factors. Colorectal Dis 10: 170-178, 2008

20. AJCC (American Joint Committee on Cancer) Cancer Staging Manual, 7th edition, Edge SB, Byrd DR, Compton CC (Eds), et al: Springer, New York. pp143, 2010.

21. Karnofsky DA and Burchenal JH: The Clinical Evaluation of Chemotherapeutic Agents in Cancer. In: MacLeod CM (Ed), Evaluation of Chemotherapeutic Agents. Columbia Univ Press, New York, pp196, 1949.

22. Schwartz LH, Litière S, de Vries E, Ford R, Gwyther S, Mandrekar S, Shankar L, Bogaerts J, Chen A, Dancey J, et al: RECIST 1.1-Update and clarification: From the RECIST committee. Eur J Cancer 62: 132-137, 2016.

23. Siegel RL, Fedewa SA, Miller KD, Goding-Sauer A, Pinheiro PS, Martinez-Tyson D and Jemal A: Cancer statistics for Hispanics/Latinos, 2015. Cancer J Clin 65: 457-480. 2015.

24. Sturgeon CM, Duffy MJ, Stenman UH, Lilja H, Brünner N, Chan DW, Babaian R, Bast RC Jr, Dowell B, Esteva FJ, et al: National Academy of Clinical Biochemistry laboratory medicine practice guidelines for use of tumor markers in testicular, prostate, colorectal, breast, and ovarian cancers. Clin Chem 54: e11-e79, 2008.

25. Duffy MJ, vanDalen A, Haglund C, Hansson L, Holinski-Feder E, Klapdor R, Lamerz R, Peltomaki P, Sturgeon C and Topolcan O: Tumour markers in colorectal cancer: European Group on Tumour Markers (EGTM) guidelines for clinical use. Eur J Cancer 43: 1348-1360, 2007.

26. Romero-Ventosa EY, Blanco-Prieto S, González-Piñeiro AL, Rodríguez-Berrocal FJ, Piñeiro-Corrales G and Páez de la Cadena M: Pretreatment levels of the serum biomarkers CEA, CYFRA 21-1, SCC and the soluble EGFR and its ligands EGF, TGF-alpha, HB-EGF in the prediction of outcome in erlotinib treated non-small-cell lung cancer patients. Springerplus 4: 171, 2015. 